\title{
CARACTERIZAÇÃO E FUNCIONAMENTO DA REFUTAÇÃO EM DEBATE ELEITORAL
}

\author{
Gustavo Ximenes Cunha ${ }^{\mathrm{a}}$
}

\begin{abstract}
RESUMO: No trabalho, realizado com base em proposiçóes teóricas e metodológicas da Escola de Genebra, procuramos focalizar a maneira como a refutação é utilizada por Dilma Rousseff (PT) e Aécio Neves (PSDB), em excerto do último debate eleitoral da campanha presidencial de 2014. Com a análise, verificamos que a estratégia adotada pelos adversários de trocarem refutações implica a realizaçáo de um processo de negociação altamente complexo e agressivo para as faces em jogo.
\end{abstract}

PALAVRAS-CHAVE: refutação; processo de negociação; debate eleitoral.

Recebido em: 31/05/19

Aprovado em: 18/09/19

1

os últimos anos, as pesquisas desenvolvidas no âmbito dos estudos da linguagem sobre o debate eleitoral têm focalizado especialmente dois aspectos do gênero que são complementares, mas distintos: i) ou se estudam questóes mais amplamente interacionais, como as restriçóes materiais e simbólicas impostas pelo veículo de comunicação produtor do debate e o impacto que essas restrições e a assunção dos papéis sociais de candidatos/ adversários ou de jornalistas/moderadores exercem sobre o comportamento verbal ou não verbal dos interlocutores (AQUINO, 2008; MARTEL, 2008;

a Professor da Faculdade de Letras da UFMG e do Programa de Pós-Graduação em Estudos Linguísticos da UFMG. ORCID: 0000-0001-9953-1204. E-mail: <ximenescunha@yahoo. com.br>. 
SULLET-NYLANDER; ROITMAN, 2009; SILVA, 2013; KERBRAT-ORECCHIONI, 2017), ii) ou se estudam propriedades (micro)linguísticas de exemplares do gênero, como os recursos sintáticos e lexicais utilizados pelos adversários políticos para, ao elaborarem atos de fala, tais como perguntas e críticas, construírem, geralmente de forma agressiva/impolida, imagens identitárias (BLAS-ARROYO, 2003; SOUZA; FERRARI, 2003; KERBRAT-ORECCHIONI, 2010; FRACCHIOLLA, 2011; FRACCHIOLLA; ROMAIN, 2015; BATISTA; ANDRADE, 2017; MARQUEZ, 2017; CUNHA, 2015, 2017).

Neste trabalho, procuramos focalizar um aspecto que talvez tenha recebido menos atenção por parte dos estudiosos do gênero debate eleitoral, a saber, a maneira como se desenvolve o processo de negociação entre os adversários políticos, o que implica a descrição de como atos de fala determinados se inserem e se articulam aos demais na dinâmica da estruturação do sistema de turnos (HARRIS, 2001; KERBRAT-ORECCHIONI, 2010; CUNHA; MARINHO, 2017; CUNHA; BRAGA, 2018). Neste trabalho, o ato de fala focalizado é a refutação, por ser esse um ato que, tendo como característica essencial permitir a seu produtor mostrar-se em desacordo com o responsável por asserção previamente produzida (MOESCHLER, 1980, 1982; BRANDÁO, 1998), possui um valor ilocucionário que se identifica com a finalidade central do gênero debate eleitoral ${ }^{1}$.

Para realizar esse estudo, valemo-nos de contribuições teóricas e metodológicas da abordagem genebrina para o estudo da organização do discurso. Essa abordagem se desenvolveu em torno de Eddy Roulet, na Universidade de Genebra, razão pela qual também é conhecida como Escola de Genebra (KERBRAT-ORECCHIONI, 2006). No final dos anos 1970, quando surgiu essa vertente dos estudos da linguagem, o intuito de seus proponentes era elaborar um modelo de análise capaz de descrever o modo como os atos de fala, tradicionalmente estudados de forma isolada e descontextualizada no âmbito

1 Em linhas gerais, a finalidade desse gênero é não só permitir a candidatos a um cargo público apresentarem suas propostas de governo, mas também (ou sobretudo) permitir que cada candidato defenda que suas propostas e opinióes são econômica, ética e socialmente superiores às do(s) adversário(s), para, com isso, construir para si uma imagem pública oposta àquela construída pelo(s) adversário(s) (BLAS-ARROYO, 2003; SILVA, 2013; KERBRAT-ORECCHIONI, 2017; CUNHA; BRAGA, 2018). 
da Teoria dos Atos de Fala (AUSTIN, 1962; SEARLE, 1995), se articulam na estrutura de discursos dialogais e monologais autênticos (não fabricados pelo próprio pesquisador) (MOESCHLER, 1985, ROULET et al., 1985). Com base em postulados de Bakhtin/Vološinov (1986[1928]) e Benveniste (1989) - segundo os quais o diálogo é a forma primeira e básica do discurso, da qual todas as demais são derivadas, mesmo as mais aparentemente monológicas, como um romance -, os pesquisadores da Escola de Genebra elaboraram um modelo da estrutura hierárquica do discurso que lhes permitiu alcançar uma descrição bastante rigorosa do modo como, em qualquer forma de interação, ocorre o processo de negociação entre os interlocutores (ROULET et al., 1985; MOESCHLER, 1985).

A partir dos anos 1990, a finalidade dos pesquisadores passa a ser, aprimorando o modelo inicialmente desenvolvido, descrever a organização do discurso em toda a sua complexidade. Entendendo o discurso como o resultado da combinação de informaçóes de três dimensóes (linguística, textual e situacional), essa abordagem incorpora contribuiçóes de estudiosos que se centraram em aspectos isolados dessa organização, como os tipos e sequências discursivas, a construção da cadeia referencial/tópica e os aspectos suprassegmentais (fonoprosódicos) do discurso (ROULET; FILLIETTAZ; GROBET, 2001). Nessa perspectiva, tanto a produção quanto a interpretação do discurso são entendidas como fenômenos complexos que envolvem a combinação de informaçôes linguísticas (sobre as estruturas sintáticas e os itens lexicais), textuais (sobre a estrutura hierárquica do texto e o processo de negociação de que essa estrutura é o reflexo) e situacionais (sobre os parâmetros dos contextos de produção e recepção). Para dar conta da complexidade da organização do discurso, evidenciando o modo como as várias informações linguísticas, textuais e situacionais se combinam, a abordagem genebrina adota uma metodologia modular de análise (ROULET; FILLIETTAZ; GROBET, 2001)2.

$\mathrm{Na}$ etapa inicial dessa abordagem, quando se buscava um modelo para o estudo da articulação dos atos de fala no discurso, são de especial importância as contribuiçóes de Moeschler (1980, 1982, 1985) acerca da relação entre

2 Um histórico da abordagem genebrina para o estudo da organização do discurso encontra-se em Roulet (1999). 
estrutura do texto e argumentação. Nesses trabalhos, a preocupação do autor recai sobre a descrição das propriedades estruturais, linguísticas e enunciativas de atos de fala específicos, como a refutação, a asserção, a resposta, bem como de sua inserção na estrutura de interaçóes polêmicas, em que se verifica um desacordo entre os interlocutores. Por isso, para este trabalho, que se ocupa da refutação em um gênero de interação, o debate eleitoral, marcado pela polêmica, será essencial a caracterização da refutação proposta por Moeschler (1980, 1982).

Para revelar o funcionamento da refutação no debate eleitoral, estudaremos um excerto do último debate da campanha presidencial de 2014, do qual participaram os então candidatos à Presidência da República, Dilma Rousseff (candidata à reeleição pelo Partido dos Trabalhadores - PT) e Aécio Neves (candidato pelo Partido da Social Democracia Brasileira - PSDB) ${ }^{3}$. A escolha desse corpus de análise se justifica pelo fato de que, até o presente momento no Brasil, esse foi o último debate eleitoral de que participou um presidente eleito, já que, na campanha presidencial de 2018, o candidato eleito se recusou a participar dos debates eleitorais. Além disso, como esse foi o último debate eleitoral de que participou a então Presidenta Dilma Rousseff, que, após ser reeleita em 2014, foi vítima de um processo de impedimento (impeachment), concluído em 2016, esse debate possui uma evidente importância histórica.

Para realizar o estudo da refutação nesse debate, apresentaremos, inicialmente, os instrumentos de análise com os quais a abordagem genebrina para o estudo da organização do discurso descreve o processo de negociação entre os interactantes e a estrutura hierárquica resultante desse processo. Em seguida, caracterizaremos o ato de refutação, apoiando-nos, como exposto, em propo-

3 A filmagem do debate, promovido pela Rede Globo, pode ser acessada em: <http://g1.globo. $\mathrm{com} /$ politica/eleicoes/2014/transcricao-debate-presidencial-2-turno.html>. O excerto analisado encontra-se no anexo deste trabalho. A transcrição que realizamos tomou como ponto de partida a que está disponível no site onde coletamos a filmagem. Porém, na busca por uma transcrição que correspondesse ao processo de negociação efetivamente desenvolvido pelos adversários, a transcrição do excerto disponível no site foi refeita a partir da audição da passagem correspondente e com a utilizaçáo das convençóes de transcriçáo adotadas em grande parte dos trabalhos da Escola de Genebra (cf. Anexo). A numeração presente no excerto se refere à sua segmentação em atos. $\mathrm{O}$ ato é a unidade mínima de análise da abordagem genebrina (ROULET; FILLIETTAZ; GROBET, 2001). 
siçóes de Moeschler (1980, 1982). Por fim, com base nesses instrumentos de análise, realizaremos o estudo do excerto do debate eleitoral selecionado.

\section{O processo de negociação e a estrutura do texto}

$\mathrm{Na}$ abordagem genebrina, a estrutura do texto reflete o processo de negociação ao longo do qual os interactantes fazem proposições, reagem positiva ou negativamente a essas proposiçóes, expressando seu acordo ou seu desacordo, elaboram contraproposiçôes, ratificam reaçóes, sinalizando o fim da interação, estabelecem diferentes relaçóes entre as informaçóes do texto, para torná-lo mais adequado à interação, etc. Dois princípios gerais balizam esse processo ou o comportamento dos interactantes: o de completude dialógica e o de completude monológica (ROULET; FILLIETTAZ; GROBET, 2001; FILLIETTAZ, 2005; MARINHO; CUNHA, 2018; CUNHA, 2019).

- Princípio de completude dialógica: corresponde ao alcance do duplo acordo pelos interactantes, ou seja, à sua concordância sobre a possibilidade de encerramento da interação. Esse acordo é rapidamente alcançado nas interações em que, após a proposição inicial do locutor (por exemplo, um convite), o interlocutor reage favoravelmente (aceitando o convite). No entanto, quando a reação do interlocutor é desfavorável (a recusa do convite), a negociação não pode ser encerrada. Nesse caso, o locutor costuma elaborar uma contraproposição, por exemplo reiterando/reformulando o convite.

- Princípio de completude monológica: corresponde à necessidade de que cada etapa do processo de negociaçáo - proposição, reação, contraproposição ou ratificação - seja elaborada de forma adequada tanto do ponto de vista comunicativo (elaboração de intervenção suficientemente clara) quanto do ponto de vista ritual (atendimento das exigências de face e território dos interactantes $\left.{ }^{4}\right)$.

4 Para Goffman (1967[1955], 1973), a face corresponde à imagem de si que os interactantes reivindicam ao longo de dada interação, enquanto o território corresponde aos direitos que cada interactante reivindica e à defesa desses mesmos direitos. 
A representação do processo de negociação faz-se com o auxílio de estruturas hierárquicas, que são compostas por três constituintes textuais:

- trocas: unidades dialogais máximas, as trocas são formadas pelas intervençóes que materializam as proposições, reaçóes, contraproposições e ratificações de uma negociação;

- intervençóes: unidades monologais constitutivas da troca, as intervenções podem apresentar configuraçóes simples - apenas um ato - ou podem apresentar configuraçóes complexas e serem formadas por vários atos, intervençóes e mesmo trocas subordinadas;

- atos: unidades textuais mínimas, os atos correspondem à menor unidade delimitada por uma e outra passagem da memória discursiva (conhecimentos partilhados entre os interactantes).

Do ponto de vista estrutural, essas unidades se ligam por relaçóes de dependência (a presença de um constituinte depende da presença de outro, o que faz com que um seja principal e o outro subordinado), independência (a presença de um constituinte não está ligada à presença de outro, sendo, por isso, coordenados) ou interdependência (um dos constituintes não existe sem o outro, como ocorre em troca formada por pergunta e resposta ou convite e aceite) (ROULET; FILLIETTAZ; GROBET, 2001; MARINHO; CUNHA, 2018). Já do ponto de vista funcional, cada unidade da estrutura hierárquica de uma interação se liga a informações previamente estocadas na memória discursiva por dois tipos de relaçóes discursivas: as ilocucionárias e as interativas. Cada um desses tipos abarca categorias genéricas de relações.

As relações ilocucionárias definem as funções das intervenções constitutivas da troca e, portanto, estão ligadas ao princípio de completude dialógica. Essas relaçóes podem ser iniciativas ou reativas. As iniciativas (pergunta, pedido e asserção) definem a relação que a primeira intervenção de uma troca estabelece com a intervenção seguinte. Já as reativas (resposta e ratificação) definem a relação que a última intervenção de uma troca estabelece com a intervenção anterior. Quanto às intervenções intermediárias de uma troca, elas vão se caracterizar por duas funçóes ao mesmo tempo, 
uma reativa, que a liga à intervenção anterior, e uma iniciativa, que a liga à intervenção seguinte (ROULET, 2006) $)^{5}$.

Já as categorias de relaçôes interativas definem as relações entre os constituintes da intervenção e, assim, estão ligadas ao princípio de completude monológica. As categorias de relaçóes propostas nesse quadro teórico são: argumento, contra-argumento, reformulação, topicalização, sucessão, preparação, comentário, clarificação (ROULET; FILLIETTAZ; GROBET, 2001; ROULET, 2006). O locutor, ao estabelecer uma relação interativa, evidencia sua tentativa de produzir uma intervenção adequada, que permita ao interlocutor desenvolver o processo de negociação. Já o interlocutor, se avalia a intervenção previamente produzida como inadequada, pode iniciar uma negociação secundária, que se materializa em uma troca subordinada ligada a essa intervenção por uma relação de clarificação (MARINHO; CUNHA, 2018).

Tanto as relaçóes ilocucionárias quanto as interativas são categorias genéricas de relaçôes de discurso. Por isso, cada relação abarca um conjunto de relaçôes específicas. Por exemplo, a relação interativa de argumento é uma categoria genérica que abarca as relaçóes específicas de causa, argumento potencial, exemplificação, argumento suplementar etc. (ROULET, 2006). Já a relação ilocucionária de resposta abarca as relações específicas de aceitação, confirmação, se o respondente deseja sinalizar o acordo com o interlocutor, e de recusa, réplica, refutação, se o respondente deseja sinalizar o desacordo com o interlocutor (MOESCHLER, 1980, 1982).

Quanto às marcas das relaçóes de discurso, as ilocucionárias podem ser sinalizadas por diferentes categorias de marcadores. Aproximando o modo de expressão do valor ilocucionário e a abordagem das implicaturas de Grice (1975), Roulet (1980; ROULET et al., 1985) propóe três categorias de mar-

5 Nessa abordagem, diferentemente da Teoria dos Atos de Fala, o valor ilocucionário corresponde à função que liga uma intervenção às demais intervençóes da troca e náo uma propriedade inerente a um ato. Isso porque, como observa Moeschler (1994), a função ilocucionária de qualquer ato é apreendida apenas em contexto e nunca de forma descontextualizada. Assim, o mesmo ato pode exercer diferentes funçóes ilocucionárias, dependendo da troca de que participa. Por exemplo, ao mesmo ato "Você chegou tarde hoje" podem ser atribuídas, pelo menos, duas funçôes ilocucionárias: demanda de informação, se a reação do interlocutor é "Cheguei às onze da noite" (interação pai-filho), ou pedido/ordem, se a reação do interlocutor é "Já já te entrego o relatório" (interação patrão-empregado). 
cadores: a dos denominativos (verbos performativos que nomeiam a função ilocucionária (1)), a dos indicativos (expressões adverbiais que indicam a função ilocucionária por implicação convencional (2)) e a dos potenciais (verbos, sobretudo os modais poder, dever, querer, que sugerem a função ilocucionária por implicação conversacional generalizada $(3)^{6}$ (ROULET, 1980, p. 84).

(1) Eu te peço que feche a porta.

(2) Feche a porta, por favor.

(3) Você pode fechar a porta?

Por sua vez, as relaçóes interativas podem ser marcadas por conectores (mas, portanto, ou seja, aliás, onde, enquanto etc.), bem como por estruturas sintáticas, como o deslocamento de constituintes à esquerda, sinalizando a relação de topicalização (ROULET et al., 1985; ROULET; FILLIETTAZ; GROBET, 2001; MARINHO; CUNHA, 2018).

No item de análise, procederemos ao estudo da forma como os então candidatos à presidência da República, Dilma Rousseff e Aécio Neves, desenvolveram o processo de negociação em excerto do último debate ocorrido na campanha de 2014. Ainda que nossa análise vá contemplar todo o processo de negociação correspondente ao excerto, nosso olhar estará voltado, como já exposto, sobretudo para as refutaçóes elaboradas pelos candidatos. Por isso, antes da realização da análise, apresentaremos, no próximo item, uma caracterização da refutação.

\section{Algumas propriedades linguísticas, textuais e interacionais da refutação}

Em seu amplo estudo sobre a negação e sobre o ato de refutação, Moeschler $(1980,1982)$ o descreve por meio de suas condições de emprego, de seus

6 Conforme Roulet (1980), não há uma classe de marcadores que corresponda à implicação conversacional particular, porque, nesse caso, a realização da inferência, ou seja, a percepção da função ilocucionária é fortemente dependente de um contexto específico e não das marcas linguísticas. É o que ocorre, por exemplo, com o ato "Está ventando muito aqui" com valor de pedido para fechar uma janela (ROULET, 1980, p. 84). 
marcadores linguísticos, de uma tipologia de refutaçóes e de suas funções no trabalho de face (face work). Neste item, retomamos, em grandes linhas, esse estudo, apresentando essas propriedades da refutação e ressaltando os aspectos que serão importantes para a compreensão do modo como as refutações são utilizadas pelos candidatos no excerto do debate que analisaremos ${ }^{7}$.

A refutação caracteriza os atos com os quais o locutor defende a falsidade de asserção previamente produzida pelo interlocutor. Nesse sentido, a refutação pertence à categoria das relaçóes ilocucionárias reativas, porque liga uma intervenção (a que refuta) à intervenção imediatamente anterior (a que é objeto da refutação). Mais especificamente, a refutação constitui uma categoria específica da relação genérica de resposta, porque permite ao seu produtor evidenciar que, com sua resposta, expressa seu desacordo em relação à asserção prévia do interlocutor. Tendo em vista a natureza fortemente dialógica da refutação, Moeschler (1982, p. 70-74) propóe que a produção de uma refutação (ou a atribuição da função de refutação a ato ou intervenção de uma troca) está ligada a quatro condiçóes de emprego, a saber:

- de conteúdo proposicional: o conteúdo do ato ou intervenção deve estar em relação de contradição com a proposição de asserção prévia ${ }^{8}$;

- de argumentatividade: o responsável pela refutação deve justificá-la, trazendo argumentos a seu favor;

- de sinceridade reflexiva: o responsável pela asserção prévia (objeto da refutação) deve acreditar que o responsável pela refutação acredita na falsidade dessa asserção;

- interacional: o interlocutor, aquele cuja asserção se refuta, deve avaliar a adequação da refutação. Se o interlocutor a aprova, o ato é realizado; se a reprova, o ato fracassa.

7 Com objetivos distintos dos nossos, Brandão (1998, p. 69-95) realiza uma apresentação da proposta de Moeschler (1982) acerca da refutação, relacionando-a a diferentes abordagens dos estudos da argumentação, como a Nova Retórica, de Perelman e Tyteca (2005 [1970]), e a Teoria da Argumentação na Língua, de Anscombre e Ducrot (1988).

8 Moeschler (1982) observa que essa condição tem como implicação evidenciar que entre os interlocutores há um desacordo. 
Quanto à marcação linguística da refutação, Moeschler (1982, p. 82-87) propóe quatro categorias de marcadores?

- marcadores denominativos: verbo performativo refutar, bem como os verbos do mesmo paradigma, como contestar, negar, discordar, desmentir;

- marcadores indicativos: expressóes metalinguísticas, como "não é verdade", "é falso", "é mentira";

- marcadores potenciais: itens lexicais como erro, engano, equívoco, bem como diferentes formas de negação (não, nem, nunca, jamais, de modo algum etc.);

- conectores que indicam ou confirmam a função refutativa do ato ou intervençáo que introduzem: ao/pelo contrário, mas, no entanto etc.

Ainda que a relação de refutação apresente as características gerais definidas até o momento, um ato ou intervenção pode refutar a asserção prévia de diferentes maneiras, opondo-se a todo o conteúdo proposicional dessa asserção, corrigindo um elemento de sua estrutura semântica ou ainda contestando uma de suas condiçóes de emprego. Assim, a consideração do escopo da refutação permite a Moeschler (1982) propor uma tipologia de refutaçóes ${ }^{10}$. Para o autor, as refutaçóes podem ser classificadas como retificação, refutação proposicional e refutação pressuposicional.

Com a retificação, o locutor refuta (corrige) um elemento da estrutura semântica da asserção prévia: um dos argumentos do predicado (1), o predicado (2) ou a relação de predicação entre o predicado e seus argumentos (3):

9 A proposição das três primeiras categorias segue de perto a proposta de Roulet (1980), apresentada no item anterior, de aproximar o modo de expressão do valor ilocucionário e a proposta das implicaturas de Grice (1975).

10 Embora a tipologia proposta pelo autor tenha como finalidade classificar apenas refutaçóes negativas, ou seja, em que há marcas de negaçáo, consideramos que essa tipologia pode auxiliar na compreensão das refutaçôes como um todo, mesmo daquelas que não apresentam formas de negação, já que toda refutação nega (contesta, reprova) a asserção a que está ligada. 
(1) João não comprou laranjas, mas maçãas.

(2) João não fala, mas grita.

(3) Não foi João que ajudou Ana, mas Ana que ajudou João.

Com a refutação proposicional, o locutor não corrige uma asserção prévia, mas refuta todo o conteúdo proposicional dessa asserção. Esse tipo de refutação costuma ser acompanhado de uma justificativa que pode ou não ser introduzida por um conector argumentativo, como porque, uma vez que, já que:

\section{A: O filme X é genial!}

B: Esse filme não é genial, porque não foi premiado em nenhum lugar (MOESCHLER, 1982, p. 96).

Com a refutação pressuposicional, o locutor não refuta o conteúdo proposicional de uma asserção prévia, mas uma pressuposição dessa asserção:

A: João parou de fumar.

B: João não parou de fumar, porque ele nunca fumou (MOESCHLER, 1982, p. 97).

A justificativa que costuma acompanhar esse tipo de refutação corresponde à inversão da pressuposição que subjaz à asserção refutada. $\mathrm{Na}$ troca, a justificativa de B ("ele nunca fumou") inverte a pressuposição da asserção de A ("João fumava”). Moeschler (1982) observa que uma das condições de emprego (ou, nos termos da Teoria dos Atos de Fala, de "felicidade") da asserção é o interlocutor aceitar como verdadeira a pressuposição dessa asserção, assim como uma das condiçóes de emprego da promessa é o locutor ter o interesse e a capacidade de cumpri-la no futuro. Consequentemente, quando o interlocutor produz uma refutação pressuposicional, contesta exatamente uma das condições de emprego da asserção. Por esse motivo, a refutação pressuposicional, diferentemente dos outros dois tipos de refutação, possui uma natureza metacomunicativa (MOESCHLER, 1982).

É essa natureza metacomunicativa da refutação pressuposicional que faz o autor chamar a atenção para o fato de que a escolha do tipo de refutação 
(retificadora, proposicional ou pressuposicional) promove consequências interacionais distintas. Conforme Moeschler (1982, p. 102), "uma refutação pressuposicional tem por objeto mais o enunciatário do que sua enunciação (na medida em que ela o coloca diretamente em causa)". Por isso, "ela é mais ameaçadora para a face positiva (necessidade de ser reconhecido e apreciado pelo outro) do enunciatário". Com base no grau de ameaça que os tipos de refutação representam para a face do interlocutor, o autor dispóe os tipos de refutação na escala presente na Figura 1.

Figura 1: Escala do grau de ameaça dos tipos de refutação

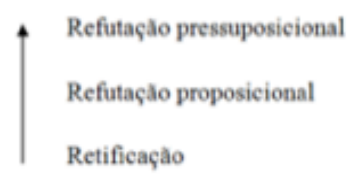

Fonte: MOESCHLER (1982, p. 102).

Em função das propriedades da refutação (condições de emprego, marcadores linguísticos, subtipos e funçóes no trabalho de face), Moeschler (1980, 1982) observa que a presença da refutação em uma interação traz consequências importantes para o desenvolvimento e a estruturação dessa interação. Se o interlocutor aprova a refutaçáo do locutor, ou seja, se ele concorda com as objeçóes expressas na refutação, a interação encerra-se e os interlocutores alcançam a completude dialógica (duplo acordo). É o que ocorre em uma interação como esta:

A: O filme X é ótimo!

B: Não é ótimo, porque tem um roteiro muito banal.

A: É verdade. Não tinha pensado dessa forma. 
Porém, se, como costuma ocorrer em interaçóes marcadas pela polêmica e pelo desacordo (ROULET, 1989; AMOSSY, 2017; CUNHA, 2019; CUNHA; TOMAZI, 2019), o interlocutor reprova a refutação, ela passa a constituir a asserção prévia que será contestada por nova refutação, como ilustra este diálogo:

\section{A: O filme X é ótimo!}

B: Não é ótimo, porque tem um roteiro muito banal.

A: Mas não é só isso que faz um filme ser ótimo...

B: Para mim, a qualidade do roteiro é essencial!

A atitude de reprovar a refutaçáo impede o alcance do duplo acordo e provoca ou o desenvolvimento do processo de negociação principal ou a abertura de negociaçóes secundárias, com o fim de alcançar a completude monológica da refutação ${ }^{11}$. Nesse sentido, a recorrência da refutação e de sua reprovação auxilia os interlocutores a desenvolverem um processo de negociação marcado pela polêmica e pelo desacordo (CUNHA, 2019).

No item a seguir, veremos como as proposiçôes teóricas apresentadas acerca do processo de negociação e da refutação são relevantes no estudo do excerto do debate eleitoral protagonizado por candidatos à Presidência da República. Nessa análise, estudaremos o processo de negociação completo, mas focalizaremos, em especial, as refutaçóes elaboradas pelos adversários, com o intuito de compreender, sobretudo, as implicaçóes que essas refutaçóes trazem para o desenvolvimento do próprio processo de negociação e para a (des)construção conjunta de faces.

\section{O processo de negociação e a refutação em um debate eleitoral presidencial}

Como já exposto, analisaremos um excerto do último debate eleitoral do segundo turno das eleiçóes presidenciais de 2014, debate protagonizado

11 No próximo item, verificaremos que a possibilidade de uma refutação provocar ou o desenvolvimento do processo de negociação principal ou a abertura de negociaçóes secundárias está ligada ao tipo de refutaçáo. Enquanto a retificação e a refutação proposicional permitem ao locutor dar sequência ao processo de negociaçáo, a refutação pressuposicional lhe permite iniciar negociaçóes secundárias. 
pelos então candidatos à Presidência da República, Dilma Rousseff (PT) e Aécio Neves (PSDB). Nesse excerto, participaram não só os candidatos, mas também o moderador (jornalista William Bonner), o que faz do excerto um trílogo (KERBRAT-ORECCHIONI, 1995) (cf. Anexo). Esse excerto corresponde a uma passagem do terceiro bloco do debate, passagem que se compóe de pergunta, resposta, réplica e tréplica.

O interesse no estudo dessa passagem, cuja temática é reforma política e financiamento de campanhas eleitorais, está no fato de ela não só trazer ocorrências de refutação, mas também apresentar uma organização macroestrutural que contraria em parte as expectativas ligadas ao gênero debate sobre como tipicamente se estrutura uma passagem composta por pergunta, resposta, réplica e tréplica. Nesse gênero, espera-se que cada candidato produza sua intervenção em momentos pré-definidos e não fale durante o momento reservado ao adversário, o que implica um desenvolvimento linear das intervenções constitutivas das trocas (CUNHA, 2017a). Como verificaremos com a análise, os interactantes, no excerto escolhido, contrariam essa expectativa, quando, a partir da produção de uma refutação por um dos candidatos durante o momento reservado à fala do adversário, passam a desenvolver um processo de negociaçáo mais complexo e agressivo para as faces em jogo.

$\mathrm{Na}$ parte inicial da troca, a interação entre os adversários caracteriza-se por uma estrutura de pergunta, feita por Aécio, e resposta, dada por Dilma. A pergunta do candidato sobre reforma política e sobre a atuação da adversária no governo ("quem tá governando o Brasil/ candidata//") é seguida por resposta em que Dilma, após afirmar ser ela quem governa o país ${ }^{12}$, apresenta como proposta de reforma política "o fim do financiamento empresarial das campanhas". Nesse ponto, a interação entre os adversários é interrompida pelo moderador, que, com uma intervenção metadiscursiva sobre o fim do tempo de fala da candidata ("tempol candidatall”), inicia uma negociação secundária cuja finalidade é informar/relembrar normas do debate. Do ponto de vista estrutural, essa intervenção abre uma troca subordinada com função de

12 Como exposto na Introdução, em 2014 Dilma Rousseff era a Presidenta da República e, nessa campanha, disputava a reeleição. 
comentário metadiscursivo $^{13}$ à intervenção de Dilma. A candidata poderia ter reagido à intervenção do moderador, dizendo "sim" ou "obrigada [pelo aviso]", mas opta por não desenvolver essa troca, permanecendo em silêncio. A figura 2 traz a estrutura hierárquico-relacional que representa o processo de negociação desenvolvido até este ponto do excerto ${ }^{14}$.

Figura 2: Estrutura hierárquico-relacional 1

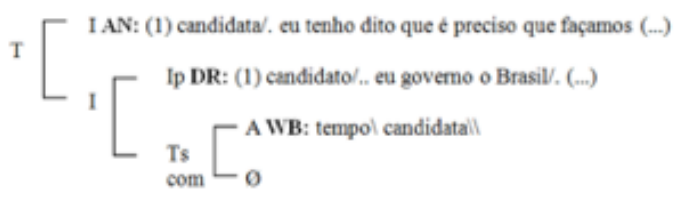

Fonte: ELABORAÇÃO PRÓPRIA.

Ao iniciar a intervenção seguinte, Aécio, ao dizer "(1) a candidata aqui nos brinda com uma pérolall. (2) quer dizer que a senhora é contra o financiamento privado//”, produz, no ato (01), um comentário metadiscursivo sobre a resposta da adversária com o qual prepara a pergunta. Com a pergunta "(2) quer dizer que a senhora é contra o financiamento privado//", o candidato evidencia que a intervenção previamente produzida pela adversária é inade-

13 Conforme definição proposta por Cunha e Braga (2018, p. 185), o comentário metadiscursivo corresponde à "relação de discurso por meio da qual o locutor emprega um segmento de discurso representado para comentar, avaliando, uma informação da memória discursiva cuja origem é o comportamento linguageiro do próprio locutor (comentário metadiscursivo autofônico), do interlocutor (comentário metadiscursivo diafônico) ou de terceiro (comentário metadiscursivo polifônico)".

14 Esta estrutura e as demais estruturas presentes neste item são construídas com as seguintes abreviaturas: $\mathrm{T}=$ troca, $\mathrm{I}=$ intervenção, $\mathrm{A}=$ ato, $\mathrm{p}=$ principal, $\mathrm{s}=$ subordinado, $\mathrm{com}=$ comentário, $\arg =$ argumento, cla $=$ clarificação, $\varnothing=$ elipse de intervenção ou silêncio do locutor quando a produção de uma intervenção era esperada, DR = Dilma Rousseff, $\mathrm{AN}=$ Aécio Neves, WB = William Bonner. Tendo em vista nossos objetivos, não representamos nas estruturas todas as relaçóes ilocucionárias e interativas que os interlocutores estabelecem entre constituintes de trocas e intervençóes. 
quada para o desenvolvimento do processo de negociação ou não atende ao princípio de completude monológica, porque não traz uma informação (qual é, de fato, a posição da adversária em relação ao financiamento privado de campanhas), informação de que ele necessita para produzir uma ratificação ou uma contraproposição. Por isso, com a pergunta, o candidato inicia uma negociação secundária que se materializa em uma troca subordinada com função de clarificação.

Sem esperar a resposta da adversária, que, no momento, não tem o direito de fala, mas tomando por certa uma resposta afirmativa sua, Aécio dá sequência à sua intervenção, dizendo “(3) candidata/". Porém, nesse ponto, Dilma, contrariando expectativas do debate acerca da distribuição do tempo de fala entre os candidatos, como indica o recobrimento de fala (termos sublinhados), o interrompe e responde: "(1) empresarial/ candidatoll (2) o senhor está esquecendoll. (3) empresarial ll”. A resposta de Dilma é a primeira refutação do excerto em análise, refutação que, com base na tipologia proposta por Moeschler (1982) e exposta no item anterior, pode ser classificada como retificação. Afinal, com essa refutação, a candidata corrige parte do conteúdo proposicional da pergunta feita por Aécio ("financiamento privado"). A natureza retificadora dessa refutaçáo elaborada pela candidata pode ser mais bem apreendida, quando se reconstrói a refutação a partir da proposição corrigida: "Não sou contra o financiamento privado, mas contra o financiamento $\mathrm{em}$ presarial".

Porque a resposta de Dilma contraria expectativas do debate no que se refere às normas de distribuição do tempo de fala dos adversários, o moderador, nesse momento, a interrompe, informando: "candidata/ a senhora precisa aguardar que ele respondall”. Com esse ato, o moderador abre nova troca subordinada com função de comentário metadiscursivo, por meio da qual relembra as normas que estruturam a interação entre os adversários. À proposição inicial dessa troca subordinada aberta pelo moderador Dilma poderia ter reagido positivamente ("sim" ou "peço desculpas") ou negativamente ("não" ou "preciso me manifestar agora"). Mas, sem aguardar a resposta da candidata, quem intervém nesse momento é o adversário, que, complementando o ato do moderador, pergunta: "vamos manter as regras//". 
Tanto o ato do moderador, quanto o do adversário possuem a mesma função. Com ambos os atos, eles abrem uma troca subordinada com função de comentário metadiscursivo à intervenção de Dilma, repreendendo-a e revelando que o momento em que a intervenção foi produzida é inapropriado e que, por isso, essa intervenção apresenta problemas de natureza ritual, por invadir o território - o tempo de fala - do adversário. Dessa forma, a objeção que seus atos trazem recai não sobre o conteúdo da intervenção de Dilma, mas sobre a enunciação dessa intervenção ou sobre a ação mesma de produzi-la.

Como os atos do moderador e do candidato têm a mesma função, é necessário verificar o tipo de relação de discurso que os liga (se ilocucionária ou interativa), bem como a unidade textual que compóem (se troca ou intervenção). Com a pergunta "vamos manter as regras//", o candidato subordina retroativamente a regra enunciada pelo moderador ("a senhora precisa aguardar que ele responda”), fazendo dessa regra um argumento para a conclusão trazida em sua pergunta: "vamos manter as regras//" Nesse sentido, os atos do moderador e do candidato formam uma intervenção e não uma troca, já que eles não se ligam por relações ilocucionárias (como, por exemplo, pergunta $\mathrm{e}$ resposta ou convite e aceite), mas por uma relação interativa de argumento, que pode ser sinalizada por conector conclusivo: "candidata/ a senhora precisa aguardar que ele respondall [portantolentão/sendo assim] vamos manter as regras//". Nessa perspectiva, os dois atos formam uma intervenção que, na troca subordinada que inicia, se liga à intervenção seguinte por uma relação de pergunta (relação genérica) e advertência/repreensão (relação específica).

Esses atos e os problemas que levantam para a análise de discursos autênticos (não produzidos pelo próprio analista) ilustram a pertinência, para o estudo desse tipo de corpus, da distinção proposta por Roulet (ROULET et al., 1985) entre os parâmetros dialogal-monologal e monológico-dialógico. Enquanto o par dialogal-monologal se refere à produção do discurso por um (monologal) ou dois (dialogal) locutores, o par monológico-dialógico refere-se à unidade textual produzida pelo(s) locutor(es): intervenção (monológica) ou troca (dialógica). Porque esses parâmetros são independentes, é possível, como na intervenção formada pelos atos produzidos pelo moderador e por um dos candidatos, que uma unidade monológica (intervenção) seja dialogal, ou seja, produzida por dois locutores, desde que os constituintes produzidos por eles 
se articulem por meio de relação interativa (argumento, comentário, reformulação) e não ilocucionária (pergunta, pedido, resposta). É provável que esse fenômeno estrutural, possivelmente raro em diálogos, seja comum em trílogos e polílogos, como é o caso de debates eleitorais.

Nessa troca aberta pelo moderador e pelo adversário, a advertência trazida na intervenção "candidata/ a senhora precisa aguardar que ele respondall vamos manter as regras//" ataca a face de Dilma, porque, como exposto, recai não sobre o conteúdo da refutação produzida previamente pela candidata (“(1) empresarial/ candidatol\ (2) o senhor está esquecendoll. (3) empresariall।”), mas sobre uma de suas condiçóes de emprego (o momento adequado para se falar e para se fazer uma refutaçáo). Dessa forma, a abertura da troca coloca a candidata na condição ou posição inferior de participante da interação a quem se podem fazer advertências e cujo comportamento, explicitamente apontado como desviante em relação às regras de conduta previstas para um debate, pode ser alvo de repreensóes. O fato de essas advertências e repreensóes serem feitas em público e ao vivo, durante um debate eleitoral, agrava seu grau de agressividade para a imagem pública de candidata à Presidência que Dilma buscava construir nesse ponto do debate ${ }^{15}$.

Nessa negociação secundária iniciada pelo moderador e pelo adversário, Dilma não produz qualquer resposta à advertência elaborada por eles e permanece em silêncio. Com isso, o moderador produz uma contraproposição, em que reelabora sua proposição inicial ("(1) vamos retomar do começoll. (2) cinquenta segundos para o candidato Aécio Neves|l”). A essa contraproposição Aécio reage positivamente, agradecendo: “(1) agradeço sua gentileza e a da candidatall.”. Com esse agradecimento, encerra-se esse processo de negociação secundário, já que o moderador e a candidata não produzem uma ratificação, que poderia ter se materializado em fórmulas de agradecimento, como "de nada" ou "não há de quê". A Figura 3, complementando a anterior, traz a estrutura que representa todo o processo de negociação até este ponto do excerto.

15 Vale lembrar ainda que Dilma era, à época, a Presidenta da República. Como evidencia Harris (2001), em estudo sobre debates no parlamento britânico, ataques à face da personalidade política de maior poder de um país são potencialmente mais agressivos e, por isso, contribuem para tornar o debate mais atrativo enquanto espetáculo midiático. 
Figura 3: Estrutura hierárquico-relacional 2

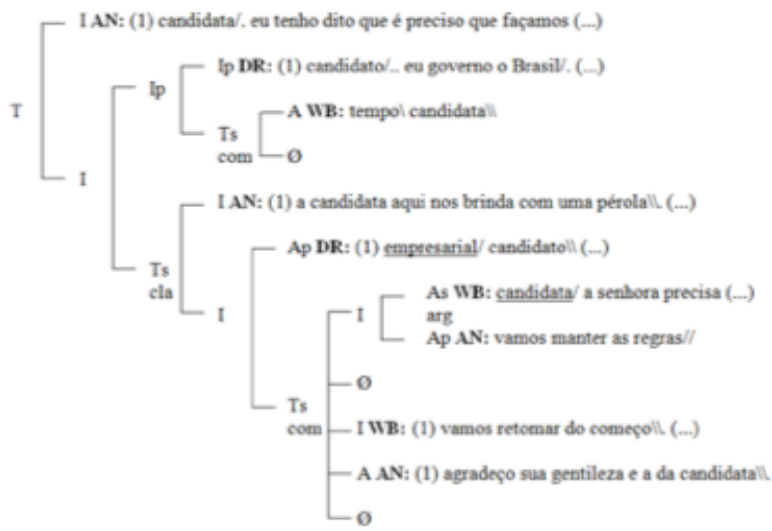

Fonte: ELABORAÇÃO PRÓPRIA.

Após realizar o agradecimento com que encerra a troca subordinada analisada anteriormente, Aécio retoma a refutação, feita previamente por Dilma (“(1) empresarial/ candidatoll (2) o senhor está esquecendoll. (3) empresariall|”), para refutá-la (“(2) candidata/ o ano passado/ um ano não eleitoral/. (3) o seu partido/ o PT/ recebeu oitenta milhões de reais em doaçôes empresariais candidatall. (4) o senhor seu partido não tem autoridade para falar sobre issoll.”). Com isso, uma refutaçâo, a de Dilma, passa a constituir o objeto de nova refutação, a de Aécio, no desenvolvimento da interação. Como apontado ao final do item anterior, esse procedimento de fazer de uma refutação objeto de nova refutação é comum em interações fortemente polêmicas (ROULET, 1989; AMOSSY, 2017; CUNHA, 2019).

Ao produzir a refutação, o candidato faz objeções sobre a completude monológica da refutação previamente elaborada pela adversária, mostrando que essa refutaçáo é, para ele, inadequada tanto do ponto de vista comuni- 
cativo (não haveria a diferença sugerida pela adversária entre financiamento empresarial e privado), quanto do ponto de vista ritual (o partido da candidata, o PT, e, consequentemente, a própria adversária enquanto representante do partido não teriam legitimidade/autoridade para defender essa forma de financiamento de campanhas). Por questionar pressupostos e condiçóes de emprego da refutação de Dilma, a refutação de Aécio possui uma natureza metacomunicativa e, por isso, pode ser classificada como pressuposicional. Com essa refutação pressuposicional, o candidato inicia uma negociação secundária ou abre uma troca subordinada com função de clarificação. Essa troca é subordinada em relação à intervenção formada pela refutação da candidata e pela troca metadiscursiva analisada anteriormente.

Nesse ponto do debate, o moderador interrompe o candidato, para, assim como em passagens anteriores, iniciar uma negociação secundária com informação sobre o fim do tempo de fala do candidato ("(1) candidato/ o seu tempo está esgotadoll. (2) tréplica da candidata Dilmall”). Com essa intervenção, ele abre uma troca subordinada à intervenção de Aécio, troca cuja função é a de comentário metadiscursivo, por pontuar as regras do debate. Nessa troca, não há reação do candidato à proposição do moderador.

À refutação elaborada pelo adversário Dilma reage negativamente, dizendo "(1) candidato/.. fim do financiamento empresarial/ é diferente. do fim do financiamento privadoll. (...)”. Com essa intervenção, a candidata contesta a refutação feita previamente pelo adversário, desenvolvendo a que havia elaborado ("(1) empresarial/ candidatoll (2) o senhor está esquecendoll. (3) empresarial \”). Desse modo, a refutação que a candidata produz agora é também retificadora, por reiterar e explicitar a diferença entre financiamento empresarial e financiamento privado. Além disso, com essa refutação, a candidata busca trazer argumentos para, opondo-se às afirmaçóes do adversário, defender que não há problemas com a forma de financiamento de sua campanha e que ela tem autoridade para tratar desse assunto.

Nesse momento, há nova interrupção do moderador, que, com o ato “(1) candidata/ tempo esgotadoll.”, inicia nova negociação secundária (troca com função de comentário metadiscursivo) sobre o fim do tempo de fala da candidata. $\mathrm{O}$ moderador não espera a reação da candidata e, com o ato "(2) a senhora já pode fazer a pergunta para o candidato Aécioll”, sinaliza/impóe 
o fim da negociação em curso e anuncia/impõe o início de nova negociação formada por pergunta, resposta, réplica e tréplica, negociação que não será analisada neste trabalho. A Figura 4 representa o processo de negociação completo desenvolvido por Dilma e Aécio no excerto analisado ${ }^{16}$.

Figura 4: Estrutura hierárquico-relacional 3

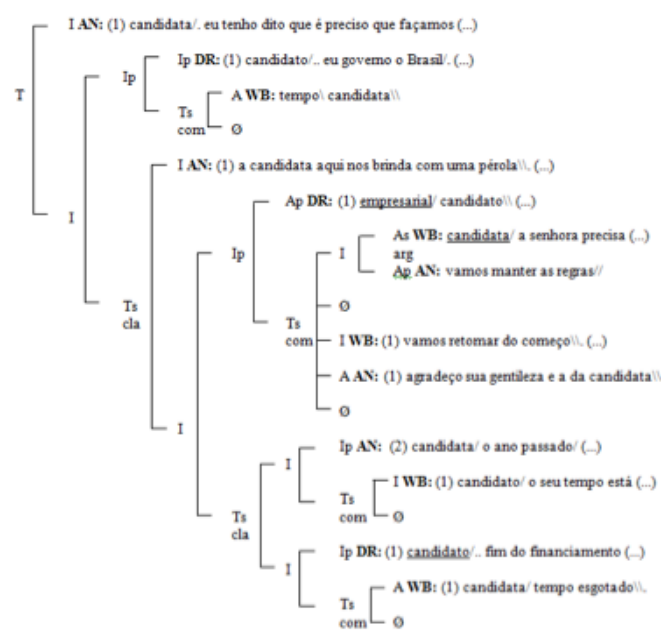

Fonte: ELABORAÇÃO PRÓPRIA.

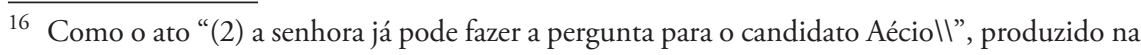
última intervenção do moderador, inicia nova troca do debate, ele não faz parte do processo de negociação em análise e, por isso, não consta da figura 4. 
Sendo o foco desta análise as refutaçôes elaboradas por ambos os candidatos, finalizamos este item chamando a atenção para diferenças funcionais e estruturais entre as refutações estudadas. A comparação da refutação pressuposicional produzida por Aécio e das refutações (retificaçôes) produzidas por Dilma revela que esses tipos de refutaçóes impactam diferentemente a estruturação da interação e o trabalho de face nela desenvolvido. Confirmando a escala de grau de ataque dos tipos de refutação (Figura 1), as retificaçóes produzidas pela candidata trazem danos para a face do adversário, já que, com elas, Dilma denuncia erro em asserçóes previamente produzidas por Aécio e ainda se mostra capaz de corrigi-lo. Porém, com suas refutaçóes, o que a candidata contesta é o conteúdo dessas asserçôes e não alguma de suas condiçôes de emprego. Já com a refutação pressuposicional, Aécio ataca, de forma mais intensa, a face de Dilma, porque, com essa refutação, questiona as condiçóes mesmas de emprego da asserção produzida pela adversária, seja a pressuposição em que se baseia, seja a legitimidade (o direito) da adversária de produzi-la.

Essa diferença, como demonstrado com as análises, tem um reflexo importante na estrutura da interação. Com as retificaçôes, Dilma produz reações negativas em relação a asserçóes prévias do adversário, o que implica um desenvolvimento linear da interação e, consequentemente, a impossibilidade do alcance iminente da completude dialógica. Já com a refutação pressuposicional, Aécio não produz uma reação negativa, mas questiona a completude monológica de asserção prévia (problemas comunicativos - pressuposição - e rituais - legitimidade), o que promove a interrupção do processo de negociação principal e a abertura de um processo secundário, materializado em uma troca subordinada com função de clarificação.

\section{Considerações finais}

Neste trabalho, realizado com base em proposições teóricas e metodológicas da abordagem genebrina para o estudo da organização do discurso (ou Escola de Genebra), procuramos evidenciar não só a complexidade do processo de negociação de um excerto do debate eleitoral protagonizado por Dilma Rousseff (PT) e Aécio Neves (PSDB), debate ocorrido ao final da campanha presidencial de 2014, mas sobretudo as consequências estruturais e interacio- 
nais da realização de refutações pelos adversários. Assim, a análise, ainda que focalizando um curto extrato de um único debate, permitiu a obtenção de observaçôes (e não generalizaçôes) sobre o funcionamento da refutação nesse gênero de interação.

Em debates, o processo de negociação conflituoso, em que a refutação de um candidato pode ser objeto de nova refutação pelo adversário, explica-se pela própria natureza do gênero debate eleitoral. Nesse gênero, é pouco esperado que a refutação de um candidato motive a ratificação do adversário, já que a ratificação significa o duplo acordo entre os interlocutores. Desse modo, um candidato que ratifica a refutação do adversário realiza um ataque grave contra sua própria face, cometendo uma espécie de "morte política" (KERBRAT-ORECCHIONI, 2010, 2010a). Assim, em debates, a estratégia de reprovar a refutação é um procedimento com o qual um candidato pode tentar reivindicar e estabelecer uma posição de força em relaçáo ao oponente, mantendo-se politicamente vivo.

Esse procedimento de troca de refutaçóes terá diferentes consequências para o desenvolvimento da interação, dependendo do tipo de refutação utilizada (retificação, refutação proposicional ou refutação pressuposicional). Se a refutação é uma retificação, ela corresponderá, na estrutura do processo de negociação, a uma reação negativa, promovendo um desenvolvimento linear desse processo. Ainda que, no excerto analisado, os candidatos não tenham produzido refutaçóes proposicionais, é possível levantar a hipótese de que esse tipo de refutação também permite um desenvolvimento linear da interação, tendo em vista sua semelhança com a retificação. Ambos os tipos recaem sobre o conteúdo proposicional da asserção refutada. Porém, se a refutação é pressuposicional, ela, por contestar condiçóes de emprego da asserção alvo da refutação e, desse modo, exibir uma natureza metacomunicativa, promoverá a abertura de uma negociação secundária (troca subordinada com função de clarificação), retardando o desenvolvimento da negociação principal.

Do ponto de vista do papel da refutação no trabalho de face, as refutaçóes pressuposicionais são mais agressivas para a face do responsável pela asserção refutada do que as retificaçôes. Embora retificar a fala do adversário seja uma ação nociva para sua face, a refutação pressuposicional permite ao candidato que a realiza questionar as próprias condiçôes de emprego da asserção prévia. 
Como demonstrado na análise, esse questionamento implica a contestação da legitimidade do adversário de tomar a palavra para fazer propostas ou críticas e, consequentemente, de seu próprio direito de participar da disputa política. Nessa perspectiva, verifica-se que o estudo de refutaçóes empregadas pelos participantes de um debate eleitoral é relevante para se conhecerem melhor não só as propriedades da negociação que desenvolvem conjuntamente, mas também o jogo político mais amplo de que participam.

\section{Referências}

AMOSSY, Ruth. Apologia da polêmica. São Paulo: Contexto, 2017.

ANSCOMBRE, Jean-Claude; DUCROT, Oswald. L'argumentation dans la langue. Bruxelles: Pierre Mardaga, 1988.

AQUINO, Zilda Gaspar Oliveira de. Diálogos da mídia - o debate televisivo. In: PRETI, Dino. (org.). Diálogos na fala e na escrita. São Paulo, Humanitas. 2008. p. 171-194.

AUSTIN, John Langshaw. How to do things with words. Oxford, Clarendon Press, 1962.

BATISTA, Ronaldo de Oliveira; ANDRADE, Mariana dos Santos. Descortesia em debates políticos televisivos de 1989 e de 2014: uma análise pragmática. Filologia e Linguistica Portuguesa, 19(2): 301-315, São Paulo, 2017.

BAKHTIN, Mikhail(VOLOŠINOV, Valentín). Marxismo e filosofia da linguagem. São Paulo: Hucitec, 1986[1928].

BENVENISTE, Émile. O aparelho formal da enunciação. In: BENVENISTE, Émile. Problemas de linguistica geral II. Campinas: Pontes, 1989. p. 81-90.

BLAS-ARROYO, José Luis. "Perdóneme que se lo diga, pero vulve usted a faltar a la verdade, señor Gonzáles": form and function of politic verbal behavior in face-to-face Spanish political debates. Discourse \& Society, 14(4): 395-423, Thousand Oaks, 2003.

BRANDÃO, Helena H. Nagamine Subjetividade, argumentação, polifonia: a propaganda da Petrobrás. São Paulo: Editora da UNESP, 1998.

CUNHA, Gustavo Ximenes. As relaçóes retóricas e a negociação de faces em debate eleitoral. Confluência, 47: 205-238, Rio de Janeiro 2015. 
. O papel dos conectores na co-construção de imagens identitárias: o uso do mas em debates eleitorais. ALFA, 61: 599-623, Araraquara, 2017.

. O impacto da dimensão situacional do discurso sobre a articulação textual. Calidoscópio, 15: 375-387, Porto Alegre, 2017a.

. Estratégias de impolidez como propriedades definidoras de interaçóes polêmicas. Delta: Documentação e Estudos em Linguística Teórica e Aplicada, 35(2): 1-28, São Paulo, 2019.

CUNHA, Gustavo Ximenes; MARINHO, Janice Helena Chaves. A expressão conectiva na verdade: contribuiçôes para uma abordagem polifônica dos conectores reformulativos. Signo, 42: 53-64, Santa Cruz do Sul, 2017.

.; BRAGA, Paloma Bernardino. Definindo o comentário metadiscursivo em uma perspectiva interacionista da Análise do Discurso. SCRIPTA, 22: 171-188, Belo Horizonte, .; TOMAZI, Micheline Mattedi. O uso agressivo da linguagem em uma audiência: uma abordagem discursiva e interacionista para o estudo da im/polidez. Calidoscópio, 17: 297-319, Porto Alegre, 2019.

FRACCHIOLLA, Béatrice. Politeness as strategy of attack in a gendered political debate - the Royal-Sarkosy debate. Journal of Pragmatics, 43: 24802488, Amsterdã, 2011.

.; ROMAIN, Christina. L'attaque courtoise: um modèle d'interaction pragmatique au service de la prise de pouvoir en politique. Semen : revue de sémio-linguistique des textes et discours, 40: 1-15. Paris, 2015.

GOFFMAN, Erving. On face-work: an analysis of ritual elements in social interaction. In: GOFFMAN, E. Interaction Ritual: essays on face-to-face behavior. New York: Pantheon Books, 1967[1955]. p. 5-45.

. La mise em scène de la vie quotidienne: les relations em public. v. 2. Paris: Les Éditions de Minuit, 1973.

GRICE, Herbert Paul. Logic and conversation. In: COLE, P.; MORGAN, J. L. (org.) Sintax and semantics: speech acts. New York: Academic Press, 1975. p. 41-58.

HARRIS, Sandra. Being politically impolite: extending politeness theory to adversarial political discourse. Discourse \& Society, 12(4): 451-472. Thousand Oaks, 2001. 
KERBRAT-ORECCHIONI, Catherine. Introduction. In: KERBRATORECCHIONI, Catherine; PLANTIN, Christian. (org.) Le trilogue. Lyon: Presses Universitaires de Lyon, 1995. p. 1-28.

- Análise da conversação: princípios e métodos. São Paulo: Parábola, 2006.

. Pour une analyse multimodale des interactions orales: l'expression des émotions dans les débats politiques télévisuels. Cadernos de Letra L'impolitesse en interaction : aperçus théoriques et étude de cas. Lexis $-E$ Journal in English Lexicology, HS 2: 35-60, Lyon, 2010a.

MARINHO, Janice Helena Chaves; CUNHA, Gustavo Ximenes. Investigating the role of pragmatic connectives in journalistic textual genres. Linguagem em (Dis)curso, 18: 545-563, Tubarão, 2018.

MARQUEZ, Maria Aldina. Debate eleitoral português: presidencialização e estratégias de atenuação linguística em situação de confronto politico. Linha D’Água, 30(1): 9-33. São Paulo, 2017.

MARTEL, Guylaine. Performance... et contre-performance communicationnelles: des stratégies argumentatives pour le débat politique télévisé. Argumentation et Analyse du Discours, 1: 02-12. Tel-Aviv, 2008.

MOESCHLER, Jacques. La réfutation parmi les fonctions interactives marquant l'accord et le désaccord. Cahiers de linguistique française, 1: 54-78, Genebra, 1980 .

- Dire et contredire: pragmatique de la négation et acte de réfutation dans la conversation. Berne: Peter Lang, 1982.

- Argumentation et conversation: éléments pour une analyse pragmatique du discours. Paris: Hatier-Credif, 1985.

Analyse du discours et analyse conversationnelle. In: MOESCHLER, Jacques; REBOUL, Anne. (org.) Dictionnaire encyclopédique de pragmatique. Paris: Éditions du Seuil, 1994, p. 471-492.

PERELMAN, Chaïm ; OLBRECHTS-TYTECA, Lucie. Tratado da argumentação : a nova retórica. São Palo : Martins Fontes, 2005[1970].

ROULET, Eddy. Stratégies d'interaction, modes d'implication et marqueurs illocutoires. Cahiers de linguistique française, 1: 80-103, Genebra, 1980. 
- Une forme peu étudiée d'échange agonal: la controverse. Cahiers de praxématique, 13: 7-18, Montpellier, 1989.

. Um modelo e um instrumento de análise sobre a organização do discurso. In : MARI, H. et al (org.) Fundamentos e dimensóes da análise do discurso. Belo Horizonte : Carol Borges, 1999, p. 139-171.

. The description of text relation markers in the Geneva model of discourse organization. In: FISCHER, Karen. (org.). Approaches to discourse particles. Amsterdam: Elsevier, 2006. p. 115-131.

ROULET, Eddy et al. 1985. L'articulation du discours en français contemporain. Berne: Lang.

ROULET, Eddy; FILLIETTAZ, Laurent; GROBET, Anne. Un modèle et un instrument d'analyse de l'organisation du discours. Berne: Lang, 2001.

SEARLE, John R. Expressão e significado: estudos da teoria dos atos da fala. São Paulo: Martins Fontes, 1995.

SILVA, Luiz Antônio da. Descortesia e (des)construção da imagem pública. In: PRETI, Dino; LEITE, Marli Quadros (org.) Comunicação na fala e na escrita. São Paulo: Humanitas, 2013, p. 93-120.

SOUZA, Ana Lúcia Trindade de; FERRARI, Lilian Vieira. E quero dizer que a candidata não respondeu à minha pergunta: as construções assertivas explícitas no debate político-eleitoral. Veredas, 7(1-2): 233-246,Uberlândia, 2003.

SULLET-NYLANDER, Françoise; ROITMAN, Malin. De la confrontation politico-journalistique dans les grands duels politiques télévisés : questions et préconstruits. In : BURGER, M.; JACQUIN, J.; MICHELI, R. (org.) Actes du colloque "Le français palé dans les médias: les médias et le politique", 2009. p. $01-19$. 


\title{
CHARACTERIZATION AND ROLE OF REFUTATION IN ELECTORAL DEBATE
}

\begin{abstract}
This work was based on theoretical and methodological propositions of the Geneva School. In the study, we focused on how Dilma Rousseff (PT) and Aécio Neves (PSDB), in excerpt from the last electoral debate of the 2014 presidential campaign, use the refutation. With the analysis, we verified that the candidates exchange refutations and that this strategy implies a complex and aggressive interaction for the faces.
\end{abstract}

KEY-WORDS: refutation; negotiation process; electoral debate.

\section{Agradecimentos}

Agradeço aos meus orientandos de Iniciação Científica Paloma Bernardino Braga e Daniel Martins de Brito, com quem, no quadro do projeto de pesquisa "Estrutura do discurso e processo de negociação", em desenvolvimento na Faculdade de Letras da UFMG, pude discutir tanto a análise aqui apresentada, quanto alguns textos teóricos que a subsidiaram. Os problemas que por ventura permaneçam são de minha inteira responsabilidade. 


\section{ANEXO}

\section{Transcrição ${ }^{17}$ :}

AÉCIO NEVES: (1) candidata/. eu tenho dito que é preciso que façamos uma reforma política no Brasill. (2) entre todas as propostas que tenho apresentado/. (3) conheço a as suas/. (4) acredito que temos que acabar com a reeleiçãoll. (5) vivemos a experiência da reeleiçãol (6) e o seu governo acabou por desmoralizá-lall.. (7) a Folha de São Paulo publicou há poucos dias que numa sexta-feira/ dos seus trinta e nove ministérios/ apenas quinze ministros/ estavam trabalhando/. (8) e que a senhora/ (9) ao longo dos últimos trinta e cinco dias/ (10) segundo o jornal de hoje/. (11) foi duas vezes ao palácio do planaltoll. (12) quem tá governando o Brasil/ candidata//

DILMA ROUSSEFF: (1) candidato/.. eu governo o Brasil/. (2) e governo sistemática e diuturnamentel candidatoll. (3) agora/. eu acredito que a questâo da reforma política não é a reeleição nãoll. (4) se de fato/ o senhor tá interessado em combater a corrupção/. (5) a questão mais séria da reforma política/ é o fim do financiamento empresarial das campanhas \. (6) porque com o fim do financiamento empresarial/ (7) nós acabaremos com a influência do poder econômico/. sobre as eleiçôes brasileiras\l. (8) isto candidato/. éWILLIAM BONNER: tempol candidatall

AÉCIO NEVES: (1) a candidata aqui nos brinda com uma pérolall. (2) quer dizer que a senhora é contra o financiamento privado// (3) candidata/

DILMA ROUSSEFF: (1) empresarial/ candidatoll (2) o senhor está esquecendoll. (3) empresariall\

WILLIAM BONNER: candidata/ a senhora precisa aguardar que ele respondall

18 Convençóes de transcrição: / - \ (contorno melódico continuativo ascendente, plano ou descendente), $/ /$ = $\|$ (contorno melódico conclusivo ascendente, plano ou descendente), . .. (pausa mais ou menos longa), : :: (alongamento mais ou menos acentuado), sublinhado (recobrimento de fala), [ ] comentário, risos, mudança de elocução ou de amplitude, ( ) palavra cuja compreensão é incerta, (X) sílaba incompreensível (ROULET, FILLIETTAZ, GROBET, 2001, p. 407). 
AÉCIO NEVES: vamos manter as regras//

WILLIAM BONNER: (1) vamos retomar do começoll. (2) cinquenta segundos para o candidato Aécio Neves\।

AÉCIO NEVES: (1) agradeço sua gentileza e a da candidatall. (2) candidata/ o ano passado/ um ano náo eleitoral/. (3) o seu partido/ o PT/ recebeu oitenta milhóes de reais em doaçóes empresariais candidatall. (4) o senhor seu partido não tem autoridade para falar sobre issoll. (5) a sua campanha/ é uma campanha milionáriall. (6) agora/ às vésperas do segundo turno/. (7) o seu coordenador financeiro da campanha pediu para aumentar o teto de gastos/ (8) porque náo tinha mais onde colocar. dinheiro/ candidatall. (...)

WILLIAM BONNER: (1) candidato/ o seu tempo está esgotadoll. (2) tréplica da candidata Dilmall

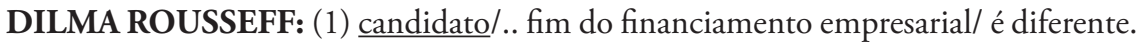
do fim do financiamento privadoll. (2) sabe por que/ candidato// (3) você pode ter financiamento de pessoas físicas/. (4) não pode de empresas l candidatoll. (5) isso acontece em várias democracias do mundoll. (...)

WILLIAM BONNER: (1) candidata/ tempo esgotadoll. (2) a senhora já pode fazer a pergunta para o candidato Aécioll 